\title{
O PADRÃo pOStURAL ENTRE OS ALUNOS ATIVOS E SEDENTÁrios No ENSINO FUNDAMENTAL
}

\author{
Carlos Gabriel da Silva e Ricardo Germano Efing \\ carlos gabriell96@hotmail.com
}

Acesso DOI: http://dx.doi.org/10.34059/ciejop.2019v27i1-16

RESUMO

O padrão postural das crianças deve ser essencialmente preservado, pois é nesta fase que mais se desenvolvem ao mesmo tempo em que o seu corpo se encontra em acomodações estruturais. Na atualidade, com o avanço tecnológico, a maioria das crianças tornou-se sedentárias, afetando suas composições anatômicas, prejudicando a saúde. Sendo assim, o objetivo deste estudo foi identificar o padrão postural entre os alunos ativos e sedentários do ensino fundamental. Utilizou-se nessa pesquisa os alunos da escola Professora Hilda Romazini Melo, União da Vitória - PR, no ano de 2018. A amostra contou com crianças de ambos os sexos, com idades entre 8 e 10 anos. $O$ instrumento de coleta de dados utilizados foi o formulário de Pate, publicado por Mota, 2012. Para a avaliação postural foi utilizado para analise o simetógrafo. Ao final do estudo chegou-se a observação de que $70 \%$ alunos foram identificados com algum tipo de desvio postural, conforme a classificação da atividade física aumenta entre os alunos, percebe-se que os desenvolvimentos dos padrões posturais se tornaram melhores. Todas estas alterações encontradas são predispostas a correções a partir de um programa de fortalecimento e alongamento muscular devidamente acompanhado e orientado de forma correta por um profissional de Educação Física.

PALAVRAS-CHAVE: Postura. Atividade física. Sedentarismo.

\section{ABSTRACT}

The postural pattern of kids must be essentially preserved, because it is in this phase that they develop the most, and at the same time, their bodies are in structural accommodations. Nowadays, due to technological advance, majority of children have become sedentary, which affects their anatomical composition, impairing their health. Therefore, the goal of this study was to identify the postural of active kids and sedentary kids in elementary school. Were used is students at Professora Hilda RomaziniMeloSchool, União da Vitória - PR, in the year 2018. The sample was composed of kids of both sexes, between the ages of 8 to 10 years old. The data collection instrument used was Pate's formulary, published by Mota, 2012. In order to do the postural assessment, it was used a simetograph. At the end of the study, it was observed that more than 70 percent of the students had any kind of postural deviation; as the amount of physical activity increased among the students, it was possible to notice that the development of their postural patterns became better. All 
of the alterations that were found are predisposed to correction by a muscular strengthening and stretching program properly accompanied and oriented by a Physical Education professional.

KEY-WORDS: Posture. Physical activity. Sedentary lifestyle.

\section{INTRODUÇÃO}

A postura é a atitude adota pelo corpo, que requer um equilíbrio musculoesquelético, onde a relação direta de suas partes com o centro de gravidade poderá realizar a proteção de todo sistema humano e ao mesmo tempo executar diversas funções e posições adotadas diretamente em sua vida (NASCIMENTO E SOUZA, 2011).

Nas crianças, a postura tem uma relevância maior, pois possuem sérias consequências, por este período ser o estirão de crescimento, onde nesta faixa etária o corpo se encontra em acomodação estrutural em sua anatomia. Na sua vida escolar, a ausência de recreação, atividades e exercícios físicos, resultam no início de processos álgicos e de enfraquecimento muscular, trazendo, por sua vez, problemas de desvios posturais.

O aumento das ocorrências de desvios posturais originários na infância, em especial relacionados com a coluna vertebral, sendo oriundo de maus hábitos posturais, como o uso de mochilas pesadas, sedentarismo, fatores sociais, hereditários e emocionais.

Na educação física escolar é imprescindível que trabalhem com os alunos nas suas múltiplas dimensões: intelectual, social, física e emocional, compreendendo o crescimento dos seus corpos e as dimensões do ser humano (DIRETRIZES CURRICULARES NACIONAIS DA EDUCAÇÃO BÁSICA, 2013).

Assim os profissionais de Educação Física têm papel fundamental neste processo, pois eles têm a capacidade e conhecimento necessários para realizarem essas atividades e ao mesmo tempo um trabalho de conscientização corporal para os estudantes, demonstrando a importância de conhecer o próprio corpo, com postura adequada para executar diferentes tarefas. 
Na infância, torna-se primordial uma vida ativa para evitar os processos de desvios posturais que interferem na estrutura musculoesquelética. Assim, elaborouse a seguinte problema de pesquisa: Qual é o padrão postural entre os alunos ativos e sedentários no ensino fundamental?

Com o objetivo de identificar o padrão postural entre os alunos ativos e sedentários no ensino fundamental.

\section{METODOLOGIA}

O presente estudo corresponde a uma pesquisa de campo, quantitativa e descritiva (LAKATOS , 2014). A população que foi estudada durante a pesquisa são os alunos do ensino fundamental da escola Professora Hilda Romazini Melo, União da Vitória - PR. A amostra se refere aos 8 alunos do quarto e 12 alunos do quinto ano, totalizando 20 alunos de ambos os sexos, com idades entre 8 e 10 anos.

Primeiramente foi realizado o formulário de Russel. R Pate o qual contem perguntas fechadas e de múltipla escolha. Cada resposta do formulário terá uma pontuação, para identificar o nível de atividade física dos alunos. Utilizou-se como método de avaliação postural a simetrografia. A mensuração dos dados sucedeu por um simetrógrafo, onde as suas linhas horizontais e verticais forneceram uma referência para o pesquisador verificar o alinhamento postural dos alunos. A $1^{\circ}$ avaliação postural aconteceu no plano frontal para identificação dos possíveis desalinhamentos contidos nele; a $2^{\circ}$ avaliação postural decorreu no plano sagital também reconhecendo os possíveis desalinhamentos contidos nele. O protocolo de avaliação postural se sucedeu através da ficha postural de Nieman (2011).

Utilizou-se como instrumento de análise e pesquisa o formulário de Russel Pate que foi traduzido e modificado por M.V. Nahas - NUPAF/UFSC, o qual contém onze perguntas relacionadas às atividades ocupacionais e de lazer, cada questão respondida sim, o pesquisador marcou os pontos à direita. A soma dos pontos é um indicativo de atividade física do sujeito, para a consideração de "ativo" a pessoa tem que atingir uma pontuação entre 12 a 20. A versão do instrumento mostrou-se prática e fidedigna entre as crianças. Esse questionário foi validado Universidade Estadual da Paraíba (Mota, 2012). 
Utilizou-se na pesquisa o protocolo de avaliação postural (Nieman, 2011) em conjunto com o simetrógrafo, para analisar o padrão postural, foi possível identificar as alterações significativas do corpo através de linhas horizontais e verticais, em relação aos seus eixos coronais e sagitais. Essas linhas foram totalmente horizontalizadas e verticalizadas dentro do aparelho Simetrógrafo. A partir dos cuidados como nivelamento do Simetrógrafo e do chão, foi realizada a avaliação postural. O aparelho tem uma mobilidade prática.

Após os resultados da avaliação postural, através da ficha postural de Nieman (2011). Foram verificados os desvios: Desnivelamento de cabeça, ombro e quadril, Projeção anterior do pescoço, Hipercifose, Hiperlordose e Pé Abduto. Após analise postural foi realizado o formulário Pate (Mota, 2012) onde a tabulação foi feita através da somatória das perguntas, após esse processo comparou o resultado na tabela que diz: 0 - 5 Inativo / 6 - 11 Modernamente ativo / 12-20 Ativo/ 21 ou mais Muito ativo. Em seguida o pesquisador comparou os resultados dos testes posturais pelo simetrógrafo com os resultados dos formulários e relacionou o padrão postural das crianças quem possuem ou não uma vida ativa.

O presente estudo foi encaminhado ao Núcleo de Ética e Bioética da Faculdade integradas do Vale do Iguaçu - Uniguaçu (protocolo 2018/114) e em seguida iniciou a pesquisa. Os alunos preencheram o Termo de livre consentimento esclarecido (TCLE) que foi assinado pelos pais e/ou responsáveis dos alunos participantes da pesquisa.

\section{RESULTADOS}

Com a realização do trabalho, primeiramente foi pesquisado quais desvios posturais estiveram mais presentes na população estudada. No Gráfico 1 estão demonstrados o número total de alunos e aqueles identificado com alguns desvios posturais de acordo com os níveis de atividades físicas.

Participaram da avaliação postural 20 (vinte) alunos, onde dessas, 14 (quatorze) tiveram algum desvio postural e apenas 6 (seis) não apresentaram nenhuma alteração em sua postura. 
Gráfico 1 - Alunos com desvios posturais

Fonte: Autor (2018)

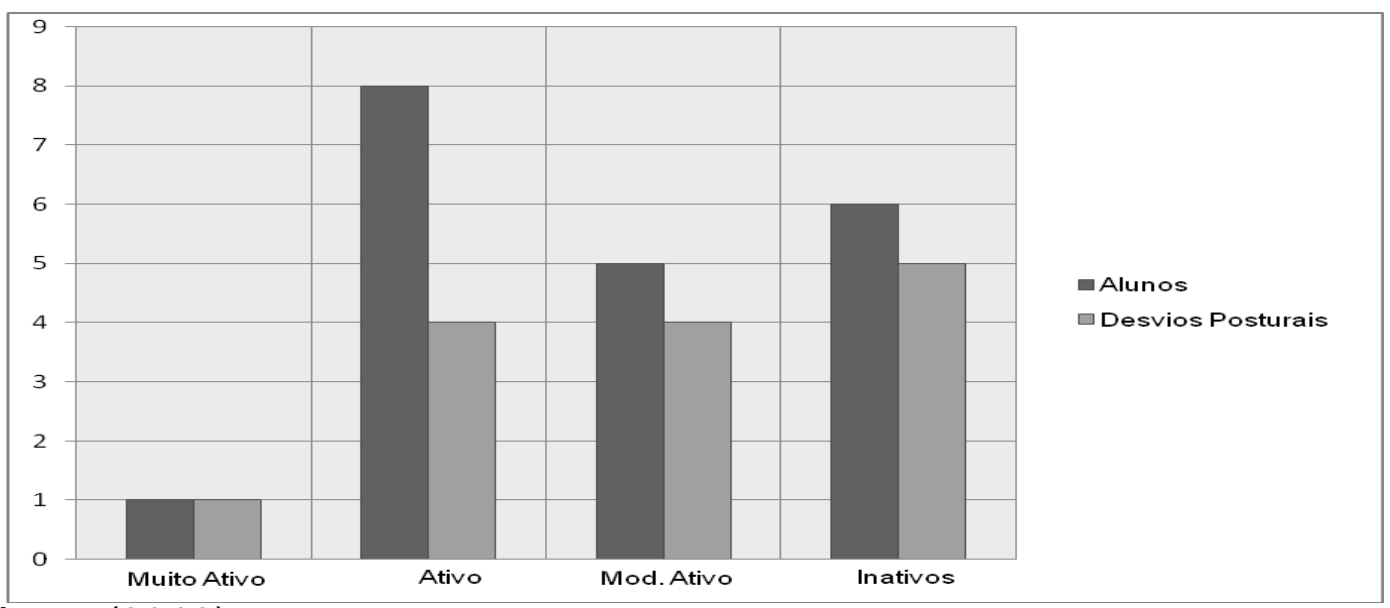

A maioria das alterações posturais tem origem na escola, devido ao uso de mochilas pesadas, ao sentar de forma inadequada e fatores ligados ao crescimento ou resultante da inadequada prática de atividade física (AZEVEDO, 2018). O desvio postural de crianças e adolescentes têm relação direta com a biodinâmica da coluna vertebral e das influências que o meio ambiente exerce nas atitudes e hábitos desenvolvidos e adotados pelos indivíduos (BRACCIALLI; VILARTA, 2000).

Após os resultados observados junto à avaliação postural com a utilização do simetrógrafo, os dados obtidos foram comparados com as respostas dos formulários preenchidos pelas crianças envolvidas na pesquisa, sendo estes comparados com respectivo nível de suas atividades físicas.

O Gráfico 2 estão representados os desvios posturais mais presentes e encontrados entre as 14 (quatorze) crianças, identificados pelo teste do simetrógrafo.

Foram constatados os seguintes dados: As 6 (seis) crianças consideradas inativas, 5 (cinco) destas têm um ou mais desvios posturais com a maior predominância Hiperlordose (4 casos), em seguida Hipercifose (3 casos), Projeção anterior do pescoço (2 casos), Pé Abduto (2 casos) e Desnivelamento de quadril (2 casos). Os 5 (cinco) alunos classificados moderadamente ativo, 4 (quatro) destes possuem desvios posturais, sendo eles Hipercifose (2 casos), Hiperlordose (2 casos) e Pé Abduto (1 caso), Desnivelamento de quadril (2 casos), Desnivelamento de ombros ( 1 caso) e Desnivelamento da cabeça (1 caso). Os 8 (oito) alunos ativos, Fórum Internacional de Qualidade de Vida e Saúde - Curitiba, 15 de junho de 2019 
4 (quatro) destes possuem alguma alteração postural, com a mesma predominância Hipercifose (2 casos), Hiperlordose (2 casos) e Projeção anterior do Pescoço (2 casos). O único aluno considerado muito ativo apresentou dois casos de desvios posturais (Pé abduto e Desnivelamento de quadril).

\section{Gráfico 2 - Desvios posturais}

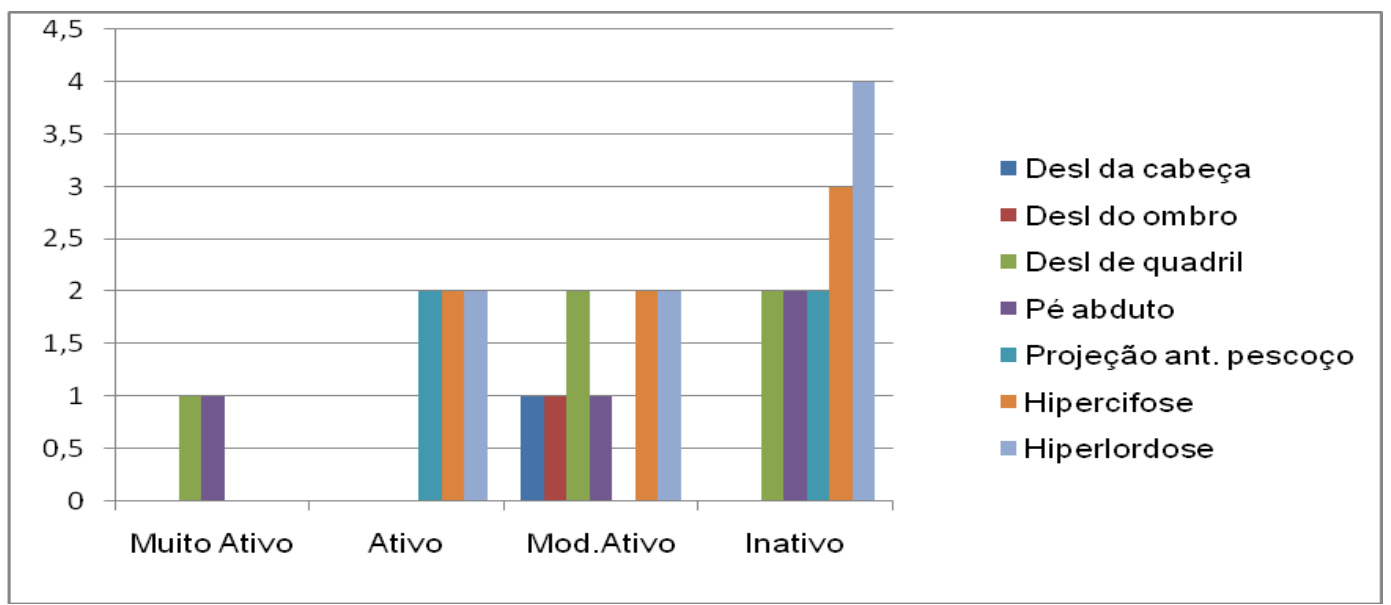

Fonte: Autor (2018)

Os principais desvios posturais encontrados são: cifose, lordose e escoliose, podendo ter uma ocorrência simples ou combinada. As deformidades podem ser classificadas de acordo com magnitude, localização, direção e etiologia (NATOUR, 2004).

O pesquisador percebeu grande número de hipercifose e projeção de pescoço. E perguntou aos avaliados se utilizavam e se passavam muito tempo usando celulares no seu dia-dia, no qual a maioria falou que sim, podendo ser a causa desse transtorno. As alterações encontradas em atletas, como a hipercifose, pode-se estar relacionada pela a utilização do celular, televisão e computador por longas horas sentadas, de forma errada e estática, o que provoca a projeção pescoço à frente, coluna curvada e pressão glútea (DOS SANTOS, 2016).

Atividades físicas em excesso podem levar o sujeito a adquirir desvio postural, principalmente quando ele conduz as suas tarefas apenas com o lado dominante do corpo, pois um lado se fortalece enquanto o outro é fraco, causando 
um desnivelamento em seu corpo, podendo se modificar em uma escoliose. o aspecto de pessoas consideradas ativas ou não com desvios posturais não tem muita relevância, se não for conduzido por profissional adequado, pois a demasia de exercício pode levar ao desenvolvimento de desvios posturais (VERDERI, 2005).

No Gráfico 3 revela o nível de gravidade de desvios posturais de acordo com a ficha de Nieman 2011.

Inativos: 13 desvios classificado, como: 9 (nove) razoáveis e 4 (quatro) inadequados; Moderadamente Ativos: 8 (oito) desvios identificados 7 (sete) foram razoáveis e 1 (um) inadequado; Ativo: 6 (seis) casos catalogados, 4 (quatro) foram considerados razoáveis e 2 (dois) inadequados; Muito Ativo: 2 (dois) desvios encontrado com classificação razoável pela ficha de padrão postural.

Gráfico 3 - Níveis de desvios posturais de acordo a ficha postural de Nieman

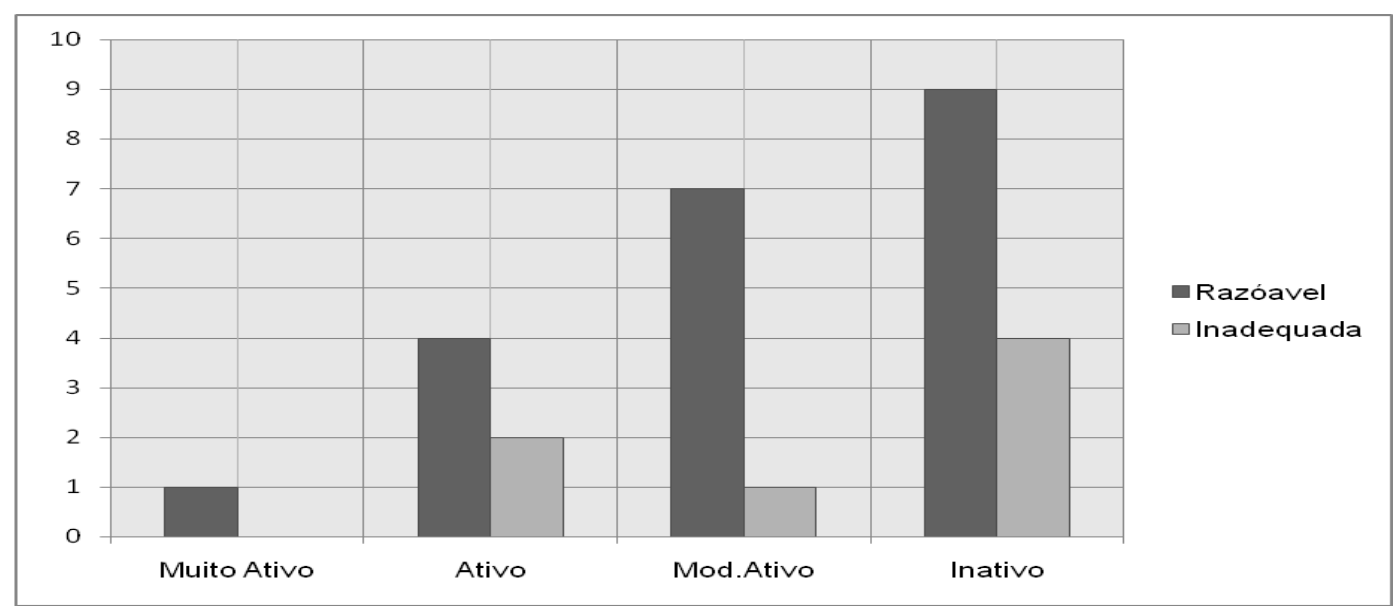

Fonte: Autor (2018)

Percebemos que quanto maior a inatividade física das crianças, maior é número de desvios posturais e suas gravidades. E quando o corpo entra em um desequilíbrio (neste caso postural), ele pode compensar com outro desvio postural em sua estrutura para tentar ajustar o desequilíbrio anterior. Atividade física se torna fator importante para manutenção da estrutura músculo esquelético, a qual é um fator determinante que pode modificar e melhorar todo sistema fisiológico do sujeito. 
Para um bom desenvolvimento corpóreo do ser humano, a coluna vertebral e os músculos a ela associados se fazem importantes, pois tais estruturais necessitam de um equilíbrio e de distribuições de forças adequadas para realização de suas atividades diárias, quando ocorre algum tipo de desvio postural o corpo obtém um desequilíbrio, provocando dores musculares e lesões na coluna vertebral, transformações ocorrem no corpo em busca do equilíbrio corporal novamente. (FERNANDES; RIBEIRO, 2018).

\section{CONSIDERAÇÕES FINAIS}

Com a realização deste trabalho, chegou-se a observação de que $70 \%$ alunos foram identificados com algum tipo de desvio postural, conforme a classificação da atividade física aumenta entre os alunos, percebe-se que os desenvolvimentos dos padrões posturais se tornaram melhores. Apenas $30 \%$ dos alunos não apresentaram alterações posturais, na qual destes $66 \%$ foram classificados como fisicamente ativos. Os desvios posturais mais encontrados entre os alunos foram hipercifose, hiperlordose e projeção anterior do pescoço. Todas estas alterações encontradas são suscetíveis a correções a partir de um programa de fortalecimento e alongamento muscular.

A atividade física é essencial para manutenção de todos os sistemas do corpo humano, tornando-se a maneira mais eficaz e menos dispendiosa, quando acompanhada e orientada de forma correta por um profissional de Educação Física, tendo a capacidade de reduzir problemas futuros.

No contexto escolar, é papel dos professores de Educação Física realizar esse trabalho, programando em suas atividades a educação do corpo, já que a postura desempenha uma função importante no desenvolvimento psicomotor, sendo esta uma fase importante na vida do ser humano. Cabe aos mesmos, a partir de seu preparo e conhecimentos prévios sobre a educação postural, intervir de maneira efetiva neste contexto a fim de trabalhar nos alunos a consciência e o desenvolvimento corporal normal, respeitando e interagindo de maneira individual a cada jovem. 
Desta maneira os problemas posturais músculos esqueléticos, podem ser precocemente evitados e tratados garantindo uma qualidade de vida e uma saúde corporal a população estudada.

\section{REFERÊNCIAS}

AZEVEDO, Rogério et al. 0 contributo da Educação Física na deteção e prevenção de problemas posturais nos alunos. Didática da educação física: perspetivas, interrogações e alternativas, p. 61-72, 2018.

BRACCIALLI, Lígia Maria Presumido; VILARTA, Roberto. Aspectos a serem considerados na elaboração de programas de prevenção e orientação de problemas posturais. Rev Paul Educ Fís, v. 14, n. 2, p. 159-71, 2000.

DIRETRIZES CURRICULARES NACIONAIS. Educação Básica. Brasília: MEC, SEB, DICEI, 2013.

DOS SANTOS, Josenei Braga et al. Perfil postural de atletas de ginástica rítmica na faixa etária de 10 a 19 anos no estado de São Paulo. RBPFEX-Revista Brasileira de Prescrição e Fisiologia do Exercício, v. 10, n. 59, p. 395-404, 2016.

FERNANDES, Bruna Sehnem; RIBEIRO, Andréa Jaqueline Prates. Desvios posturais e estilo de vida de escolares das zonas urbana e rural. Seminário de Iniciação Científica, Seminário Integrado de Ensino, Pesquisa e Extensão e Mostra Universitária, 2018.

LAKATOS, E.M. Metodologia do trabalho científico: Procedimentos básicos, pesquisa bibliográficas, projeto e relatório, publicações e trabalhos científicos. 7.ed.São Paulo: Atlas, 2014.

MOTA,A. Análise do nível de atividade física em escolares do Sítio Queimadas. Universidade Estadual da Paraíba, centro de Ciências Biológicas e Saúde, 2012.

NASCIMENTO A; SOUZA M: O papel do professor de educação física, perante a postura de crianças e adolescentes no ensino fundamental. UEPA: 2011.

NATOUR J; Coluna Vertebral. 2 ed. São Paulo : Copyright 2004.

NIEMAN: Exercício e saúde: Teste e prescrição de exercícios. 6 ed. Baueri -SP: Manoele, 2011.

VERDERI, Érica; Programa de educação postural. 3 Ed, São Paulo SP: Phorte 2005. 